\title{
Foodborne hepatitis A outbreak associated with bakery products in northern Germany, 2012
}

M Harries ${ }^{1,2,3}$, M Monazahian¹, J Wenzel4, W Jilg4, M Weber ${ }^{5}$, J Ehlers ${ }^{6}$, J Dreesman¹, E Mertens (Elke.Mertens@nlga. niedersachsen.de) ${ }^{1}$

1. Department for Infectious Disease Epidemiology, Governmental Institute of Public Health of Lower Saxony, Hannover, Germany

2. Postgraduate Training for Applied Epidemiology (PAE, German Field Epidemiology Training Programme), Robert Koch Institute, Berlin, Germany

3. European Programme for Intervention Epidemiology Training (EPIET), European Centre for Disease Prevention and Control (ECDC), Stockholm, Sweden

4. Institute of Clinical Microbiology and Hygiene, University of Regensburg Medical Center, German Consultant Laboratory for Hepatitis A and Hepatitis E, Regensburg, Germany

5. Lower Saxony State Office for Consumer Protection and Food Safety (LAVES), Institute for Fish and Fishery Products, Cuxhaven, Germany

6. Lower Saxony State Office for Consumer Protection and Food Safety (LAVES), Oldenburg, Germany

In October 2012, a hepatitis A (HA) outbreak with 83 laboratory-confirmed cases occurred in Lower Saxony. We defined primary outbreak cases as people with laboratory-confirmed HA and symptom onset between 8 October and 12 November 2012, residing in or visiting the affected districts. Secondary outbreak cases were persons with symptom onset after 12 November 2012 and close contact with primary cases. We identified 77 primary and six secondary cases. We enrolled 50 primary cases and 52 controls matched for age and sex, and found that $82 \%$ of cases and $60 \%$ of controls had consumed products from a particular bakery $(\mathrm{OR}=3.09 ; 95 \% \mathrm{Cl}: 1.15-8.68)$. Cases were more likely to have eaten sweet pastries $(\mathrm{OR}=5.74 ; 95 \% \mathrm{Cl}$ : 1.46-22.42). Viral isolates from five selected cases and three positively tested surfaces in the bakery had identical nucleotide sequences. One additional identical isolate derived from a salesperson of the bakery suffering from a chronic disease that required immunosuppressive treatment. Epidemiological and laboratory findings suggested that the salesperson contaminated products while packing and selling. Future risk assessment should determine whether food handlers with chronic diseases under immunosuppressive treatment could be more at risk of contaminating food and might benefit from HAV immunisation.

\section{Introduction}

\section{Background}

On 31 October 2012, the local health authorities of the neighbouring districts of A and B in Lower Saxony, northern Germany, detected an increase of hepatitis $A(H A)$ cases. Thirteen serologically-confirmed HA cases had been notified within three days (incidence: 7.76 per 100,000 inhabitants) whereas during October to December 2011, only one case (incidence: 0.37 per 100,000 inhabitants) was notified in the same area. Notification of laboratory-confirmed infection with hepatitis A virus (HAV) and notification of clinical cases of viral hepatitis are mandatory in Germany. From 2001 to 2011 in Lower Saxony, the incidence of notified HA cases declined substantially. Fitting a linear trend to the incidence rate per 100,000 population reveals an average reduction by 0.13 per year, from 2.13 in 2001 down to 0.78 in 2011. During this time, the proportion of cases that could be assigned to known outbreaks was $28 \%$ on annual average with a slightly increasing trend (unpublished data).

In general, the true number of infections is presumed to be higher than the number of notified cases due to underreporting and the fact that many individuals, especially children, may experience HAV infection without symptoms [1].

HAV is transmitted by the faecal-oral route, either by a direct contact with a contagious person infected with HAV or by ingestion of HAV-contaminated food or water or from contaminated surfaces [2]. The average incubation period of HA is 28 days (range: $15-50$ days) [3]. The period of highest infectiousness is assumed to range from two weeks before until one week after onset of jaundice. Viral shedding with highest HAV concentration in stool occurs before jaundice [4].

Food items that have been described or assumed to have caused HA outbreaks include mussels, oysters, 
vegetables and salad fertilised with faeces $[5,6]$, fruits including raw blueberries [7], frozen raspberries [8], frozen strawberries [9], green onions [10] and shellfish [11]. Contamination of food by infected food handlers in restaurants has also been described [12]. Several HA outbreaks have been associated with bakeries [13]. In an outbreak observed in 1968 in Michigan, United States (US), the vehicle of infection was pastries covered with glaze or icing [14]. In an outbreak in New York, US, HA was associated with sugar-glazed baked goods [15]. An HA outbreak took place in Germany in 2004 where a bakery employee most probably contaminated the products that caused the outbreak [13].

The tenacity of HAV is higher than of other non-enveloped viruses belonging to the family of Picornaviridae. The ability of HAV to survive on hands and on inanimate surfaces plays an important role for HAV transfer from hands of infectious persons to food items and from contaminated surfaces to fingertips $[16,17]$. Disinfection with alcohol and hydrogen peroxide $3 \%$ and $6 \%$ concentration) has been found ineffective against HAV on surfaces [18]. According to Mbithi, unmedicated liquid soap was ineffective for reducing virus titre on hands [18], indicating that hand washing with ordinary soap is not sufficient to prevent HAV transmission. HAV is acid-stable [19] and seems to remain viable while passing through the stomach [1]. The minimum infectious dose is estimated to be very low with $10-100$ virus particles. The amount of HAV shed by infected humans ranges from 106 to 108 virus particles per 1 gram of stool $[20,21]$.

In cooperation with local and regional public health and food safety authorities, we conducted epidemiological, laboratory and molecular investigations to identify the vehicle of the outbreak to prevent further cases. The local health authorities were aware that both of the most-affected villages had a shop of a bakery company (bakery $\mathrm{X}$ ); this bakery runs four shops in total. Additionally, during the standardised interviews, cases reported, without being asked, having observed signs of jaundice in a bakery $\mathrm{X}$ employee. Taking into consideration the literature on bakery-associated HA outbreaks [13-15], a causal link to bakery $X$ or its products was a major hypothesis for the outbreak investigation.

\section{Methods}

\section{Case definition}

Based on the regional and temporal distribution of cases, we defined primary outbreak cases as persons:

- residing in the affected districts (A or B) or having visited the outbreak area during 15 September to 03 October 2012 and

- reported with serologically-confirmed HAV infection and

- with disease onset between 8 October and 12 November 2012.
Serologically confirmed HAV infection was defined as IgM and/or IgG positive results, depending on the time lag between apparent symptoms and taking of blood sample. If sequencing data were available and did not match the outbreak strain, the person was not regarded as case. We excluded cases with travel history to HA-endemic areas during the probable period of infection.

Secondary outbreak cases were defined as persons:

- reported with serologically-confirmed HAV infection and

- suffering from HA with onset after 12 November 2012 and

- having close contact with primary outbreak cases.

In the course of the outbreak investigation, two HAVinfected persons were detected who did not meet the primary and secondary outbreak case definition but appeared to be important to clarify the outbreak. We refer to them as early cases and they were defined as persons:

- with serologically-confirmed HAV infection (IgG and IgM) and

- with symptom onset before 8 October 2012 and

- residing in the outbreak area.

Cases are described in terms of time, place and demographic information.

Case-control study

In a case-control study, we investigated the hypotheses that the occurrence of disease was associated with bakery $X$ in general, with particular food items from bakery $X$, or with other exposures like festivals and markets in the outbreak area during time of infection. We also considered well-known risk factors for HAV infection such as travelling abroad or consuming seafood.

We aimed to recruit primary outbreak cases according to the case definition with the following additional restrictions:

- at least 18 years of age and

- physical and mental state and language skills sufficient to allow successful participation in the interview and

- no household contact with the suspected early cases (because such persons might have had other routes of transmission than the majority of cases).

We recruited control persons by random-digit dialling, aiming for a case-control ratio of 1:1. We used an approach adapted to the German landline system [22] since landlines are still common in the outbreak region. The landline telephone numbers of residential cases were modified by incrementing the last two digits. This was to ensure a regional matching of controls with the cases. In addition, the controls were 
frequency-matched to the cases by sex and five-year age bands. Persons were not selected as controls if they reported symptoms of HAV infection, a history of HAV infection, or an HAV vaccination (other than recent post-exposure vaccination). For the interviews, we used standardised questionnaires for cases and controls. Both cases and controls were interviewed within two weeks after notification of the cases by trained interviewers. The exposure data were dichotomised by classifying 'don't know' and 'no reply' into one group. The associations were estimated by univariable and multivariable logistic regression analyses. All exposures were investigated and assessed by odds ratios (OR) with 95\% confident intervals (CI) and two-tailed $\mathrm{p}$-values of chi-squared test. Exposure variables with an $O R>1$ and a $p$-value<0.2 in univariable analysis were included in a multivariable logistic regression analysis. A stepwise backward elimination was used until all remaining variables were significant at the 0.05 level, keeping age and sex in the model. Statistical analyses were performed with Stata version 12.1.

\section{Laboratory diagnostics of human samples}

During their initial diagnostic workup, specimens from the cases were usually analysed in the contract laboratories used by the cases' various general practitioners. Thus, the investigating authorities did not have direct access to these samples and we performed additional laboratory investigations.

In order to compare the HAV sequences, we investigated specimens from one of the two suspected early cases, a bakery $X$ employee, together with five of the suspected primary outbreak cases, particularly primary outbreak cases who were not resident in the two affected districts, to identify whether they all belonged to the same outbreak. Blood and faecal specimens of bakery $X$ staff were screened with the aim to clarify their infection status, to detect potentially HAV positive persons and to determine whether contamination by a virus shedding employee could have been the source of the outbreak.

All serum specimens were serologically tested by enzyme immuno assay (EIA) for IgM and IgG anti-HAV using an automated system (Architect i2000SR, Abbott Diagnostics). The serum and faecal specimens were analysed for the presence of viral HAV RNA using a reverse transcription $P C R$.

\section{Environmental investigation}

We analysed surface swabs which were taken indoors in all four bakery $X$ shops (hereafter referred to as $A, B$, C, D, Figure 1). HAV RNA was isolated by using a QIAmp Viral RNA Mini Kit (Qiagen). Subsequently, a real-time reverse transcription PCR (RT-PCR) was used for detecting HAV RNA in surface specimens following the methods of Costafreda et al. [23].

\section{Genotyping/sequencing}

At the German Consultant Laboratory for Hepatitis A and Hepatitis E, HAV RNA was amplified from IgM positive serum and stool specimens as well as from positive surface specimens.

Nucleic acid isolation was performed using the RNeasy Mini Kit (Qiagen) with $100 \mu$ l elution volume (RNasefree water). A $10 \mu \mathrm{l}$ aliquot of the eluate was used for reverse transcription in a total reaction volume of 20 $\mu \mathrm{l}$ using Moloney murine leukaemia virus (M-MuLV) reverse transcriptase (Applied Biosystems) and random hexamers according to the manufacturer's instructions (42 degrees Celsius, 30 minutes). Two replicates were analysed in $30 \mu \mathrm{l}$ PCRs each containing $10 \mu \mathrm{l}$ of the

\section{TABLE 1}

Primer and probe sequence, hepatitis A outbreak, northern Germany, 2012

\begin{tabular}{|c|c|c|c|c|}
\hline $\begin{array}{l}\text { Assay and gene } \\
\text { target }\end{array}$ & Primer or probe & $\begin{array}{l}\text { Amplicon } \\
\text { size (bp) }\end{array}$ & Primer or probe sequence $\left(5^{\prime}-3^{\prime}\right)^{a}$ & $\begin{array}{c}\text { Nucleotide positions or accession } \\
\text { number }\end{array}$ \\
\hline RT-qPCR & & & & NC_001489 \\
\hline Polymerase & SH-Poly- $A^{c}$ & 107 & GARTTTACTCAGTGTTCAATGAATGT & $5964-5989$ \\
\hline Polymerase & SH-Poly-1 ${ }^{c}$ & & GGCATAGCTGCAGGAAAATT & $6051-6070$ \\
\hline Polymerase & SH-Poly-Q ${ }^{c}$ & & FAM-TCTCCAAAACGCTTTTTAGAAAGAGTCC-BHQ-1 & $5992-6019$ \\
\hline \multicolumn{5}{|l|}{ Sequencing } \\
\hline $\mathrm{VP}_{1} / \mathrm{P}_{2} \mathrm{~A}$ & $\mathrm{HAVG}^{\mathrm{d}}$ & 542 & TGTCTGGAGCACTGGATGG & $2839-2857$ \\
\hline $\mathrm{VP}_{1} / \mathrm{P}_{2} \mathrm{~A}$ & $\mathrm{HAV}_{7}^{\mathrm{d}}$ & & CATTTCAAGAGTCCACACACTTCT & $3357-3380$ \\
\hline $\mathrm{VP}_{1} / \mathrm{P}_{2} \mathrm{~A}$ & $\mathrm{HAV}^{\mathrm{d}}$ & 397 & TGGTTTCTATTCAGATTGCAAATTA & $2890-2914$ \\
\hline $\mathrm{VP}_{1} / \mathrm{P}_{2} \mathrm{~A}$ & $\mathrm{HAV}^{\mathrm{d}}$ & & TTCATTATTTCATGCTCCTCAGT & $3264-3286$ \\
\hline
\end{tabular}

NT: nucleotide.

a Hydrolysis probes were labelled with 6-carboxyfluorescein (FAM) at the 5' end and a nonfluorescent quencher (BHQ-1) at the 3' end.

${ }^{b}$ Reference sequence accession numbers are for the databases of GenBank, the European Nucleotide Archive (ENA), and the DNA Data Bank of Japan (DDBJ).

c Primer reported by Houde et al. 2007 [25].

d Primer reported by Grinde et al. 1997 [26]. 
Primary cases of hepatitis A, by residence, and bakery X shops selling bakery X goods, hepatitis A outbreak, northern Germany, 2012

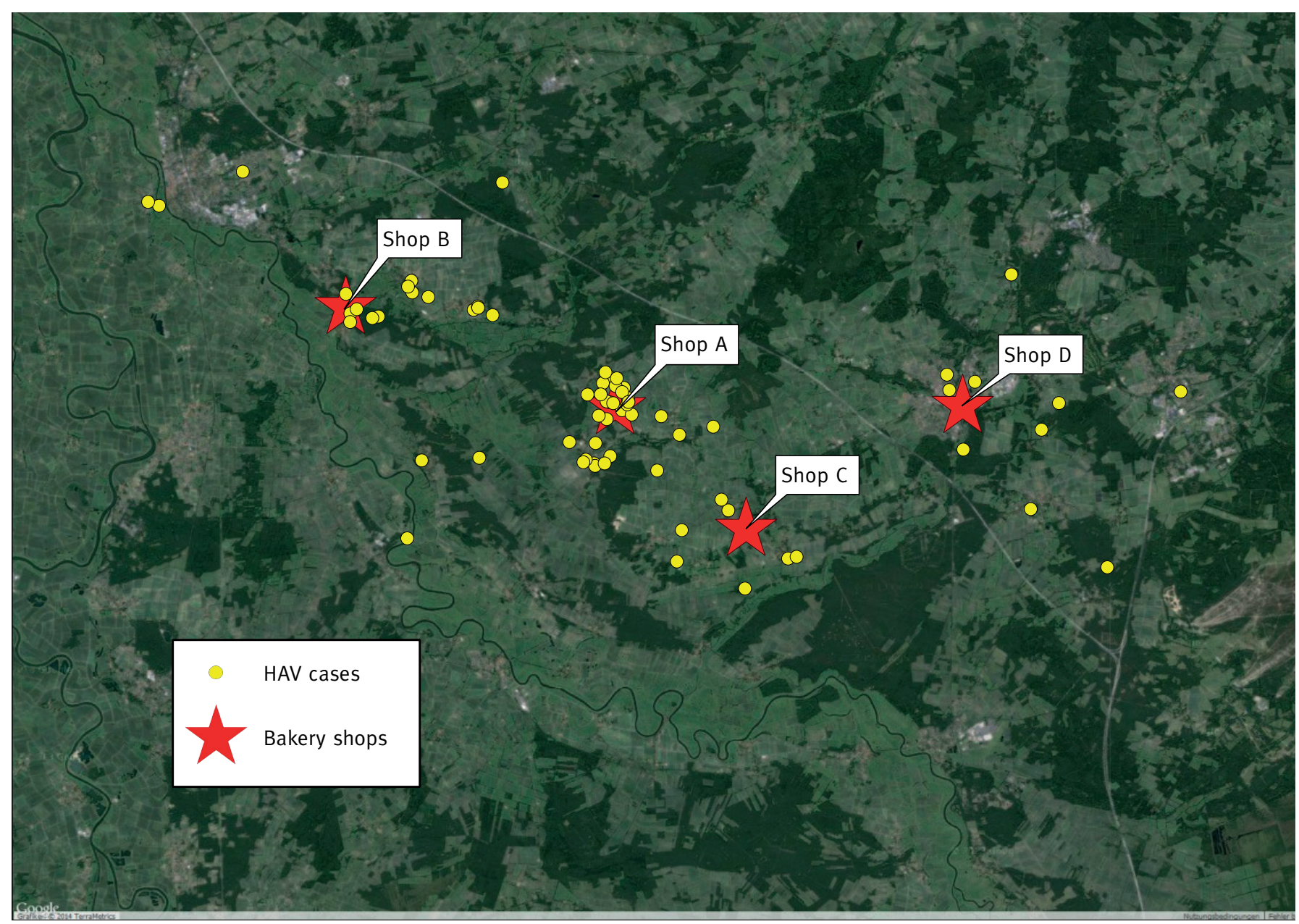

For data protection purposes, cases' home addresses were randomly distributed an average of 250m east/west and $250 \mathrm{~m}$ north/south for locations within villages, and $1 \mathrm{~km}$ east/west and $1 \mathrm{~km}$ north/south for locations outside villages.

RT product (corresponding to $5 \mu \mathrm{l}$ eluate), ROX buffer, $5.0 \mathrm{mmol} / \mathrm{l} \mathrm{MgCl}_{2}, 1.25 \mathrm{U}$ AmpliTaq Gold DNA polymerase (all Applied Biosystems), dNTPs, specific primers $(300 \mathrm{nmol} / \mathrm{l}$ each) and TaqMan hydrolysis probe (200 $\mathrm{nmol} / \mathrm{l})$. Table 1 shows the nucleotide sequences of the primers and probe used for the HAV reverse-transcription quantitative real-time PCR (RT-qPCR) assay in the viral polymerase region: SH-Poly-A, SH-Poly-1 and SH-Poly-Q [24]. Thermal cycling was performed on a StepOnePlus instrument (Applied Biosystems) and comprised a 10-minute initial enzyme activation step at 95 degrees Celsius, and 45 cycles of 95 degrees Celsius for 15 seconds and 60 degrees Celsius for 1 minute.

RT-qPCR positive isolates were further characterised by amplicon sequencing. The initial amplification was performed by using specific primers [25] for the HAV $\mathrm{VP}_{1} / \mathrm{P}_{2} \mathrm{~A}$ genomic region (HAV6, HAV7, $542 \mathrm{bp}$ ). A $2.5 \mu \mathrm{l}$ aliquot from the first round of PCR was then used as a template in the second round of PCR with primers HAV8 and HAV 9 (397 bp). The PCR products were purified by using QIAquick columns (Qiagen) and sequenced in both directions with the second-round amplification primers.

Nucleotide sequences of amplicons were determined by using the BigDye Terminator Cycle Sequencing Kit (Applied Biosystems) and separated on a model 3730xl genetic analyser (Applied Biosystems). Nucleotide sequences of PCR products were analysed by using CodonCode Aligner 4.1.1 software (CodonCode Corporation, Centerville, MA, USA).

GenBank was searched for sequences with high similarity using the BLAST and FASTA algorithms as implemented by the HUSAR Biocomputing Service at DKFZ, Heidelberg, Germany. A rooted maximum likelihood phylogenetic consensus tree for $\mathrm{VP}_{1} / \mathrm{P}_{2} \mathrm{~A}$ nucleotide sequences was inferred using PHYLIP 3.69 software. 
Age and sex distribution of primary hepatitis A outbreak cases, northern Germany, $2012(\mathrm{n}=77)$

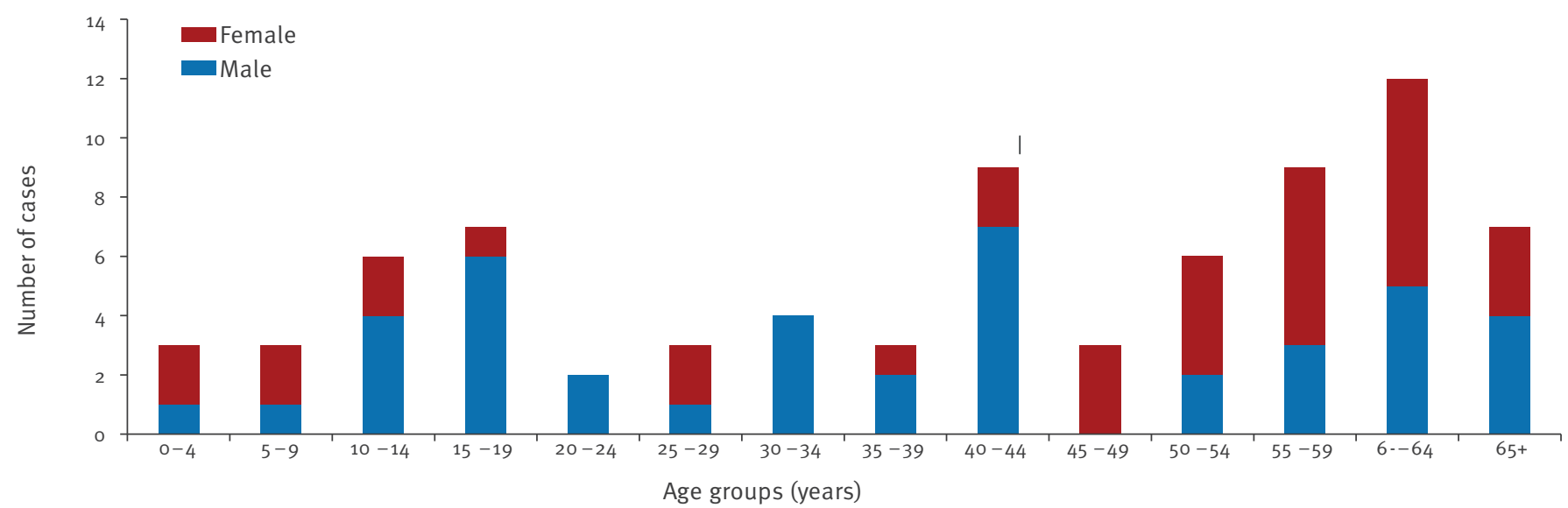

\section{Results}

\section{Descriptive epidemiology}

A total of 83 outbreak cases with disease onset between 8 October and 29 December 2012 were identified (77 primary and six secondary outbreak cases).

The median age of the primary cases was 44 years (range: $4-77$ years) and $78 \%$ of the cases $(n=61)$ were 18 years and older. A total of $45 \%$ of the cases were female (Figure 2).

We found that 77 cases (91\%) were residents of the districts of $A(n=52)$ and $B(n=25)$ in Lower Saxony. The primary cases' places of residence (not including the visitors) were clustered mainly around two bakery $X$ shops (shop A and B, see Figure 1).

Seven primary cases were visitors to A or B from different German districts during the possible period of infection (15 September-3 October 2012). Three of these seven stayed in the area for the weekend of 22-23 September 2012, two more spent a holiday from 15 to 29 September 2012, and two worked regularly in this area but lived in other districts.

Disease onset for the first primary outbreak case was 8 October 2012 (calendar week (CW) 41). The outbreak peaked in CW 43 and 44 and ended in CW 52 (Figure 3). Besides the notified cases, the outbreak investigation revealed two persons having experienced HAV infection with an earlier disease onset than the primary outbreak cases. Thus we categorised them as 'early cases'. One was a bakery $X$ employee. This person was not involved in preparing products but sold products in shop $A$ and $B$ and packed products for shop $C$ and D. Henceforward this particular employee will be referred to as 'the salesperson' (although the bakery $X$ shops had several other salespersons), and we will use the pronoun 'they'. Onset of jaundice was early October 2012 (CW 39). The other early case was a close contact with disease onset early September 2012 (CW 36 , Figure 3). These two infections only became known to the health authorities in the course of the outbreak investigation. They had not previously been notified to the surveillance system. A second employee of bakery $X$ was notified as a case, but their disease onset occurred at the peak of the outbreak ( CW 44$)$.

\section{Case-control study}

Of the total 77 primary outbreak cases, we enrolled 50 cases (including six who were not resident in district A or B) in the case-control study together with 52 frequency-matched controls. The median age of enrolled cases was 51 years (range: $18-77$ years) and of controls 52 years (range: $27-80$ years). The sex distribution was almost equal. A total of 25 of the 50 cases were female, as were $30(58 \%)$ of 52 controls.

\section{FIGURE 3}

Hepatitis A outbreak cases by reported onset of illness per calendar week, northern Germany, $2012(n=85)$

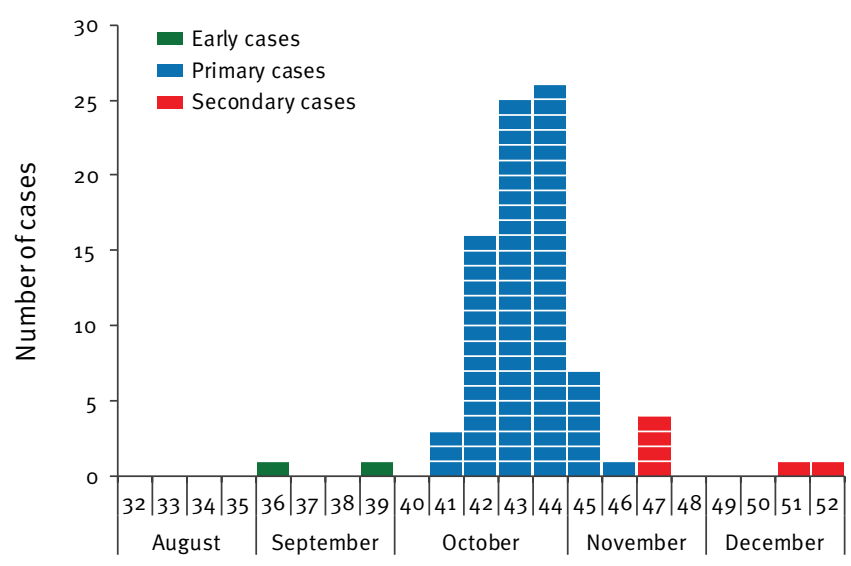

Calendar week onset of illness (CW) 
TABLE 2

Results of univariable analysis of the case-control study among cases and controls, hepatitis A outbreak, northern Germany, $2012(\mathrm{n}=102)$

\begin{tabular}{|l|c|c|c|c|}
\hline Exposure & Cases $(\mathrm{n}=50)$ & Controls $(\mathrm{n}=52)$ & OR & $95 \% \mathrm{Cl}$ \\
\hline Dried tomatoes & 5 & 3 & 1.80 & $0.39-9.63$ \\
\hline Mussels & 2 & 4 & 0.50 & $0.06-2.97$ \\
\hline Event/fair & 23 & 20 & 0.93 & 0.428 \\
\hline Frozen berries & 8 & 9 & 0.91 & $0.41-2.15$ \\
\hline Bakery X customer & 41 & 31 & 3.09 & $0.31-2.65$ \\
\hline
\end{tabular}

OR: odds ratio; $\mathrm{Cl}$ : confidence intervals.

The univariable analysis revealed a significant association between HAV infection and being a customer of bakery $\mathrm{X}$ (Table 2$)$.

A total of 41 of the 50 cases reported eating bakery $X$ products, as did 31 of 52 controls (OR: 3.09; $95 \% \mathrm{Cl}$ : 1.15-8.68; $p=0.013)$. None of the other exposures, which were unrelated to bakery $X$, was significantly associated with the disease. To find out more about the specific products of bakery $X$, we performed a nested analysis (Table 3 ) of cases and controls who were customers of the bakery. Sweet pastries (OR: 5.97; 95\% $\mathrm{Cl}: 1.43-34.91 ; \mathrm{p}=0.005)$, apple cake (OR: 3.86; $95 \%$ $\mathrm{Cl}: 0.89-23.18 ; p=0.043$ ), and Bienenstich (a German cake typically made with a custard, buttercream or cream filling) (OR: 4.68; 95\% Cl:0.87-46.58; $\mathrm{p}=0.043$ ) were significantly associated with HAV infection in univariable models. In a multivariable modelling approach adjusted for age and sex and other bakery products, only consumption of sweet pastries remained significant (ORadj: $5.74 ; 95 \% \mathrm{Cl}: 1.46-22.42 ; p=0.012)$. Five of six non-residents were among the group of bakery $X$ customers who reported having eaten sweet pastries or cake.

\section{Laboratory diagnostics}

Six persons fulfilling the spatial and temporal requirements of the primary outbreak case definition provided specimens for additional testing. In addition, specimens were collected from both the early cases. They all tested positive for recent HAV infection (IgG and IgM positive). HAV RNA in stool specimens was detected for one early case, the salesperson. No HAV RNA was available for the salesperson's contact. The salesperson suffered from an underlying condition that may prolong shedding of the virus. Follow up investigations revealed that the salesperson was shedding a large amount of $\mathrm{HAV}\left(4.5 \times 10_{4}\right.$ copies/ml) for about six months.

There were 43 other bakery staff members, of whom 14 did not provide specimens (including the HAV positive employee in (W 44). A total of 24 employees tested HAV-antibody negative. Of the remaining five, four had been vaccinated or had a previous HAV infection, results showing them to be IgG positive and IgM negative; the salesperson had an acute HAV infection, as indicated above.

\section{Environmental investigation}

Surfaces in all four bakery $\mathrm{X}$ shops were examined. Overall, 129 swabs were taken from surfaces in the kitchen, bathrooms and sales spaces. HAV RNA was detected by PCR in four swabs from two bakery shops (A and B, Figure 1) at the following locations:

\section{TABLE 3}

Results of univariable and multivariable analysis of the case-control study among bakery X customers, hepatitis A outbreak, northern Germany, $2012(\mathrm{n}=72)$

\begin{tabular}{|c|c|c|c|c|c|}
\hline \multicolumn{6}{|c|}{ Univariable analysis } \\
\hline $\begin{array}{l}\text { Exposure (products } \\
\text { of bakery } X \text { ) }\end{array}$ & $\begin{array}{l}\text { Cases exposed to } \\
\text { bakery } X(n=41)\end{array}$ & $\begin{array}{c}\text { Controls exposed to } \\
\text { bakery } X(n=31)\end{array}$ & OR & $95 \% \mathrm{Cl}$ & $p$-value \\
\hline Bread and rolls & 35 & 26 & 1.12 & $0.24-4.95$ & 0.861 \\
\hline Tarts & 6 & 1 & 5.14 & $0.56-244.26$ & 0.106 \\
\hline Apple cake & 12 & 3 & 3.86 & $0.89-23.18$ & 0.043 \\
\hline Bienenstich & 12 & 2 & 4.68 & $0.87-46.58$ & 0.043 \\
\hline Sweet pastries & 16 & 3 & 5.97 & $1.43-34.91$ & 0.005 \\
\hline \multicolumn{6}{|c|}{$\begin{array}{l}\text { Multivariable analysis } \\
\text { adjusted for age and sex }\end{array}$} \\
\hline Sweet pastries & 16 & 3 & 5.74 & $1.46-22.42$ & 0.012 \\
\hline
\end{tabular}

OR: odds ratio; $\mathrm{Cl}$ : confidence intervals. 
- cash desk and refrigerator handle (shop A)

- PC keyboard and door handle of staff toilet (shop B)

Three of the four surface specimens contained enough HAV RNA for molecular sequencing.

Analyses of food items were not conducted because no leftover samples were available.

\section{Molecular biology}

The PCR analysis for HAV demonstrated that seven human and three surface specimens contained sufficient HAV RNA to be molecularly sequenced. These 10 specimens were reanalysed using a nested PCR protocol targeting the variable $\mathrm{VP}_{1} / \mathrm{P}_{2} \mathrm{~A}$ genomic region (Table 1).

Sequence analysis of the 349 bp amplicons (PCR primer sequences not included) revealed nine isolates (three surface and six human specimens) with identical nucleotide sequences (Figure 4).

For the outbreak isolate (accession number HF677201), the closest matches in the EMBL viral sequence database (accessed April 2013) were strain TunS4-01, isolated in 2001 in Tunisia (acc. AY875664) and strain number 148 , isolated in 2007 in Germany (acc. EU416238), both with $98.9 \%$ identity. Phylogenetic analysis allowed the two novel isolates to be classified as HAV genotype I, subgenotype IA (Figure 4). Genotype and subgenotype nomenclatures were applied according to a previously proposed classification scheme [26].

One of the seven human isolates (HSCK100034 (acc. HF677202)), differs significantly from the sequence with 21 mismatches, translating into 94\% similarity (Figure 5).

Consequently, this person was not regarded as a case belonging to this outbreak. They were a sporadic visitor to the B district, had not visited to the narrower outbreak region, and had not consumed products from bakery $\mathrm{X}$.

\section{Outbreak management}

The local health authorities began management of the outbreak immediately after the first notifications. The most important measures to control the outbreak were the vaccination of all susceptible bakery $X$ employees and cases' household contacts, and the cancellation of a fair that was to be held in the most affected village. In addition, the above-mentioned laboratory testing of bakery $\mathrm{X}$ staff and surface sampling in bakery $\mathrm{X}$ were part of the control strategy, as they facilitate the exclusion of infectious staff members from work and detect contaminated surfaces in food processing facilities.

\section{Discussion and conclusions}

We described a point-source HA outbreak in northern Germany with 83 laboratory-confirmed cases who developed symptoms between 8 October and 27

\section{FIGURE 4}

Rooted maximum likelihood phylogenetic consensus tree for VP1/P2A nucleotide sequences of selected hepatitis A virus isolates, hepatitis A outbreak, northern Germany, 2012

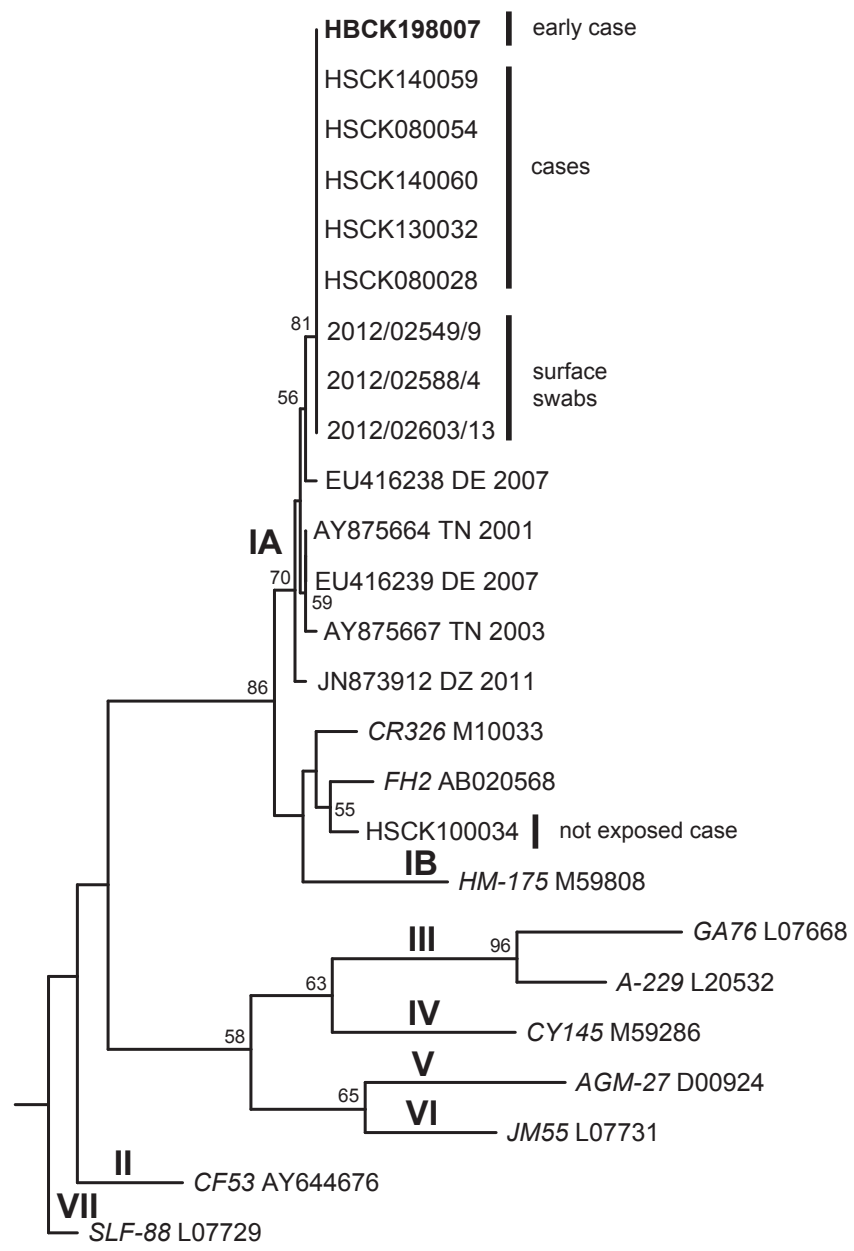

DE: Germany; TN: Tunisia; DZ: Algeria.

The sequences of the outbreak related strain cluster in Hepatitis A virus (HAV) subgenotype IA. The early case is shown in bold. The selected sequences represent the nearest homologs in GenBank and typical members of genotype I-VII (27).Genotype VII was used as an outgroup. Numbers at the nodes indicate bootstrap values of greater than $50 \%$. Sequences are denoted by GenBank ID, isolate name (reference strains in italic), International Organization for Standardization (ISO) country code and year of isolation. Sequence data from this paper have been deposited with the European Nucleotide Archive under Accession Nos. HF677201-HF677202.

December 2012. This is the largest recorded autochthonous HA outbreak since the start of standardised surveillance in Germany in 2001. By means of the case-control study, we found a significant association between HAV infections and being a customer of bakery $X$. In particular, consuming sweet pastries was identified as a significant risk factor. This epidemiological evidence is supported by the strong laboratory evidence of the molecular identity of HAV sequences of 
specimens from cases, the bakery $X$ salesperson and surfaces inside bakery $X$ shops. In addition, sequencing of non-residential cases confirmed their relation to the outbreak.

Onset of cases' symptoms and travel data from nonresidential cases indicate that the period of infection may have lasted from 15 September to 3 October 2012, but definitely covered the weekend of 22-23 September 2012. In the telephone interviews, all five visitors with sequence-identical isolates reported having eaten sweet pastries or cake (apple cake or Bienenstich) from bakery $X$. Thus, epidemiological and laboratory results suggest that contaminated bakery $X$ products were vehicles of infection.

It was not possible to test bakery $\mathrm{X}$ products for containing HAV. There were no leftover samples from the period of infection due to the short shelf life of bakery products and the long incubation period of HA.
Considering the time of the salesperson's disease onset and their work schedule, they might have worked while being infectious and contaminated baked goods and surfaces. A potential reason for sweet pastries being the vehicle of transmission could be the fact that those often are coated with fatty substances that help the virus to persist on the surface and maybe as well help to weather the acidic milieu of the stomach. Furthermore, inactivation of HAV requires heating foods to $>85$ degrees Celsius for at least one minute and sweet pastries are usually not fully baked or have unheated fillings or toppings.

Since the salesperson was suffering from a chronic disease and was treated with cortisone, the secretion of virus in their stool might have started at very high titres one to two weeks prior to their onset of illness, and continued for several months at lower titres after their jaundice occurred. One month after onset of jaundice, the titre was still at a high level $\left(4.5 \times 10_{4}\right.$ copies/ $\mathrm{ml})$.

\section{FIGURE 5}

Alignment of hepatitis A virus VP1/P2A nucleotide sequences, hepatitis A outbreak, northern Germany, 2012

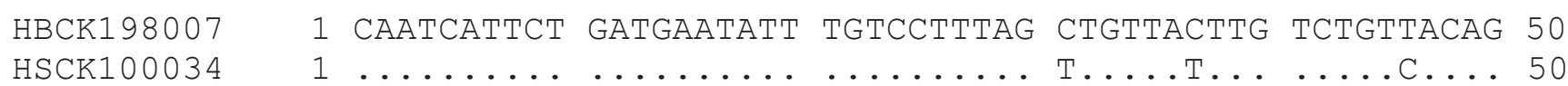

HBCK198007

HSCK1 00034

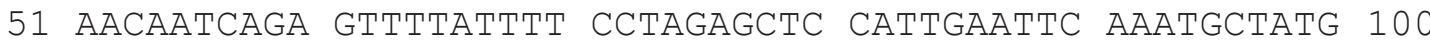

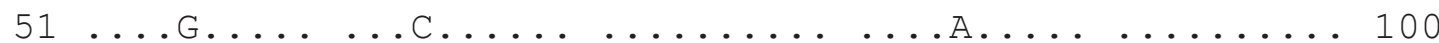

HBCK198007 101 TTGTCCACTG AGTCTATGAT GAGTAGAATT GCAGCTGGAG ACTTGGAGTC 150

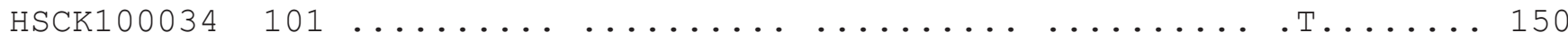

HBCK198007 151 ATCAGTGGAT GATCCTAGAT CAGAGGAGGA CAGGAGATTT GAGAGTCATA 200

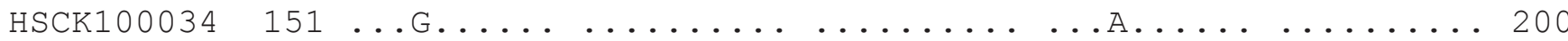

HBCK198007 201 TAgAATgtAg AAAACCATAC AAgGAATTGA GATTGgAgGt TGgGAAACAA 250

HSCK100034 $201 \ldots \ldots \ldots \ldots$. ........................ 250

HBCK198007 251 AGACTTAAAT ATGCTCAGGA AGAGTTGTCA AATGAAGTGC TTCCACCTCC 300

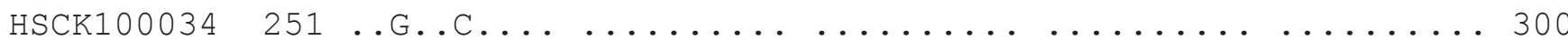

HBCK198007 301 TAGGAAAATG AAAGGGGTTT TTTCCCAGGC TAAAATTTCT CTTTTTTAT 349

HSCK100034 $301 \ldots \ldots \ldots \ldots$.......................... 349

The upper sequence was derived from the presumptive index case (HBCK198007, salesperson) and represents further eight identical sequences from five cases (serum specimen) and three surface specimens collected in the bakery X. The sequence from one notified nonresidential case differs significantly (HSCK100034, 21 mismatches, 94\% similarity). 
It remains unclear where the infected salesperson and their close contact acquired their infections. However, we learned that the salesperson had packed and sold bakery products one to two weeks prior to the onset of jaundice, which correlates with the time period the visitors reported eating bakery $X$ products. The epidemiological results may raise questions about how nine of the cases might have been exposed as they were not costumers of bakery $X$. In fact, further investigation of these cases revealed that it was very likely that they all had consumed bakery $\mathrm{X}$ products, for example when visiting the homes of other bakery $X$ customers. However, as we did not perform these extensive additional investigations for controls in the same way, we did not include this information into the case-control study's analysis.

The laboratory investigation showed that HAV-positive human and surface specimens had identical RNA sequences, while one case differed. Therefore, we excluded this case from the case-control study and the outbreak. This shows the importance of accomplishing outbreak investigation by sequence-based molecular methods which can verify or disprove an assumed epidemiological link.

As a consequence of prompt outbreak management, the cooperation of all involved parties and follow-up with the cases by the regional health authority, only six secondary cases occurred and the outbreak was interrupted.

There were several limitations. Based on the long incubation period of $\mathrm{HAV}$, a recall bias regarding the answers of consumed bakery items may have occurred. And, considering the age distribution and knowing that children have more often asymptomatic HAV infection [27], we assume that we did not identify every case.

\section{Recommendations}

Nationwide, two previously-reported HA outbreaks associated with baked goods were documented [13, 28]. In both, contamination of filled or glazed pastries by a baker was the probable source of HAV infection. Both of these conclusions were based on epidemiological evidence alone. In our study, we were able to sequence the HAV strains of the salesperson, primary cases and environmental specimens. It may be possible to avoid similar outbreaks in the future by addressing the potential spread of HAV through food handlers and educating food handlers as well as their employer to recognise hepatitis $A$ symptoms and to be aware that HAV has a long incubation period.

Considering the high tenacity of HAV, we strongly recommend the supervised use of disinfectants with virucidal activity against HAV and appropriate application of virucidal disinfection in outbreak situations.

For all food handlers, we recommend wearing plastic gloves while handling baked and unbaked products provided that correct handling is assured (e.g. changing gloves at the recommended intervals).

In view of the availability of an effective HAV vaccine [29] and several HA outbreaks with food handlers being the probable source, the evidence for the role of food handlers in HAV transmission and disease burden in Germany should be reviewed to inform a decision for a vaccination recommendation targeting food handlers.

Future risk assessment should determine whether food handlers with chronic diseases requiring immunosuppressive treatment could be more at risk of contaminating food and might therefore benefit from HA immunisation.

\section{Acknowledgements}

We sincerely thank colleagues from the local public health departments for collecting case data and sending in blood and stool specimens. Our thanks also go to all patients and controls for participating in the interviews. Finally, a warm thank you to Sandra Heidrich, Ina Holle and Nicola Jahn for conducting interviews, developing the database and entering the data.

Conflicts of interest

None

Authors' contributions

Author contribution for Foodborne Hepatitis A outbreak associated with bakery products in Northern Germany, 2012.

The work presented here was carried out in collaboration between all authors. Elke Mertens and Manuela Harries provided the surveillance and human exposure data. Johannes Dreesman, Elke Mertens and Manuela Harries designed methods and analysed the epidemiological data. Masyar Monazahian carried out the human laboratory analyses. Martina Weber investigated the environmental (surface) specimens. Joachim Ehlers was part of the response team in the veterinary section and provided the reinforcement of food control administration data. Jürgen J. Wenzel and Wolfgang Jilg carried out the molecular genetic studies of human and surface specimens including the sequence alignment. Elke Mertens and Manuela Harries interpreted the results and wrote the manuscript. All authors read and critically revised the first as well as the subsequent and final drafts of this manuscript.

References

1. Fiore AE, Feinstone S. M., Bell BP. Hepatitis A Vaccine. In: Stanley A. Plotkin WAOaPAO, editor. Vaccines. Elsevier Health Sciences, 2004: 269-297.

2. Sattar SA, Jason T, Bidawid S, Farber J. Foodborne spread of hepatitis A: Recent studies on virus survival, transfer and inactivation. Can J Infect Dis. 2000;11(3):159-63. PMID:18159284

3. Heymann DL. Control of Communicable Disease Manual. 19 ed. Washington: American Public Health Association, 2008.

4. CDC. Epidemiology of Vaccine-Preventable Diseases 2012. In: William Atkinson, Charles (Skip) Wolfe, Jennifer Hamborsky, editors. Hepatitis A. 2012.

5. Nygård K, Andersson Y, Lindkvist P, Ancker C, Asteberg I, Dannetun E, et al. Imported rocket salad partly responsible for 
increased incidence of hepatitis A in Sweden, 200-2001. Euro Surveill. 2001;6(10):151-3. PMID:11891384

6. Pebody RG, Leino T, Ruutu P, Kinnunen L, Davidkin I, Nohynek $\mathrm{H}$, et al. Foodborne outbreaks of hepatitis $\mathrm{A}$ in a low endemic country: an emerging problem? Epidemiol Infect. 1998;120(1):55-9. http://dx.doi.org/10.1017/ So950268897008340 PMID:9528818

7. Calder L, Simmons G, Thornley C, Taylor P, Pritchard K, Greening G, et al. An outbreak of hepatitis A associated with consumption of raw blueberries. Epidemiol

Infect. 2003;131(1):745-51. http://dx.doi.org/10.1017/

So950268803008586 PMID:12948375

8. Reid TM, Robinson HG. Frozen raspberries and hepatitis A. Epidemiol Infect. 1987;98(1):109-12. http://dx.doi.org/10.1017/ So95026880006177X PMID:3030789

9. Hutin YJ, Pool V, Cramer EH, Nainan OV, Weth J, Williams IT, et al.; National Hepatitis A Investigation Team. A multistate, foodborne outbreak of hepatitis A. N Engl J Med. 1999;340(8):595-602. http://dx.doi.org/10.1056/ NEJM199902253400802 PMID:10029643

10. Wheeler C, Vogt TM, Armstrong GL, Vaughan G, Weltman A, Nainan OV, et al. An outbreak of hepatitis A associated with green onions. N Engl J Med. 2005;353(9):890-7. http://dx.doi. org/10.1056/NEJMoa050855 PMID:16135833

11. Sánchez G, Pintó RM, Vanaclocha H, Bosch A. Molecular characterization of hepatitis a virus isolates from a transcontinental shellfish-borne outbreak. I Clin Microbiol. 2002;40(11):4148-55. http://dx.doi.org/10.1128/ JCM.40.11.4148-4155.2002 PMID:12409389

12. Honish L, Bergstrom K. Hepatitis A infected food handler at an Edmonton, Alberta retail food facility: public health protection strategies. Can Commun Dis Rep. 2001;27(21):17780. PMID:11709890

13. Schenkel K, Bremer V, Grabe C, Van Treeck U, Schreier E, Höhne $M$, et al. Outbreak of hepatitis A in two federal states of Germany: bakery products as vehicle of infection. Epidemiol Infect. 2006;134(6):1292-8. http://dx.doi.org/10.1017/ So950268806006212 PMID:16650329

14. Schoenbaum SC, Baker 0, Jezek Z. Common-source epidemic of hepatitis due to glazed and iced pastries. Am J Epidemiol. 1976;104(1):74-80. PMID:937343

15. Weltman AC, Bennett NM, Ackman DA, Misage JH, Campana JJ, Fine LS, et al. An outbreak of hepatitis A associated with a bakery, New York, 1994: the 1968 "West Branch, Michigan' outbreak repeated. Epidemiol Infect. 1996;117(2):333-41. http://dx.doi.org/10.1017/So950268800001515 PMID:8870631

16. Mbithi JN, Springthorpe VS, Sattar SA. Effect of relative humidity and air temperature on survival of hepatitis $A$ virus on environmental surfaces. Appl Environ Microbiol. 1991;57(5):1394-9. PMID:1649579

17. Mbithi JN, Springthorpe VS, Boulet JR, Sattar SA. Survival of hepatitis A virus on human hands and its transfer on contact with animate and inanimate surfaces. J Clin Microbiol. 1992;30(4):757-63. PMID:1315331

18. Mbithi JN, Springthorpe VS, Sattar SA. Chemical disinfection of hepatitis A virus on environmental surfaces. Appl Environ Microbiol. 1990;56(11):3601-4. PMID:2176450

19. Scholz E, Heinricy U, Flehmig B. Acid stability of hepatitis A virus. J Gen Virol. 1989;70(Pt 9):2481-5. http://dx.doi. org/10.1099/0022-1317-70-9-2481 PMID:2550575

20. Burkhardt W 3 rd. Hepatitis A Virus. In: Keith A.Lampel SA-KSMC, editor. Bad Bug Book: Foodborne Pathogenic Microorganisms and Natural Toxins Handbook. Centre for Food Safety and Applied Nutrition (CFSAN) of the Food and Drug Administration (FDA), U.S. Department of Health and Human Services. 2012: 173-177.

21. Hollinger FB, Ticehurst JR. Fields Virology Hepatitis A virus. 3 ed. Philadelphia, Lippincott - Raven: 1996.

22. Schumann S. (2012): Repräsentative Umfrage: Praxisorientierte Einführung in empirische Methoden und statistische Analyseverfahren: Oldenbourg Wissenschaftsverlag. Online verfügbar unter http://books.google.de/ books?id=asqWyiriZBoC

23. Costafreda MI, Bosch A, Pintó RM. Development, evaluation, and standardization of a real-time TaqMan reverse transcription-PCR assay for quantification of hepatitis $A$ virus in clinical and shellfish samples. Appl Environ Microbiol. 2006;72(6):3846-55. http://dx.doi.org/10.1128/AEM.02660-05 PMID:16751488

24. Houde A, Guévremont E, Poitras E, Leblanc D, Ward P, Simard C, et al. Comparative evaluation of new TaqMan real-time assays for the detection of hepatitis $A$ virus. J Virol Methods. 2007;140(1-2):80-9. http://dx.doi.org/10.1016/j. jviromet.2006.11.003 PMID:17157393
25. Grinde B, Stene-Johansen K, Sharma B, Hoel T, Jensenius $M$, Skaug K. Characterisation of an epidemic of hepatitis A virus involving intravenous drug abusers--infection by needle sharing? J Med Virol. 1997;53(1):69-75. http:// dx.doi.org/10.1002/(SICI)1096-9071(199709)53:1<69::AIDJMV12>3.0.CO;2-S PMID:9298735

26. Robertson BH, Jansen RW, Khanna B, Totsuka A, Nainan OV, Siegl G, et al. Genetic relatedness of hepatitis A virus strains recovered from different geographical regions. J Gen Virol. 1992;73(Pt 6):1365-77. http://dx.doi.org/10.1099/0022-1317-736-1365 PMID:1318940

27. Cuthbert JA. Hepatitis A: old and new. Clin Microbiol Rev. 2001;14(1):38-58. http://dx.doi.org/10.1128/CMR.14.1.3858.2001 PMID:11148002

28. Becker B, Prömse B, Krämer J, Exner M. [Transmission of pathogenic human viruses by foods: hepatitis $A$ epidemic caused by baked goods in the Euskirchen district)]. German. Gesundheitswesen. 1996;58(6):339-40. PMID:8766849

29. Fiore AE, Wasley A, Bell BP; Advisory Committee on Immunization Practices (ACIP). Prevention of hepatitis $A$ through active or passive immunization: recommendations of the Advisory Committee on Immunization Practices (ACIP). MMWR Recomm Rep. 2006;55(RR-7):1-23. PMID:16708058 